\title{
Influence of Immune Myeloid Cells on the Extracellular Matrix During Cancer Metastasis
}

\author{
David Jiang ${ }^{1} \cdot$ Su Yin $\operatorname{Lim}^{1}$ (B)
}

Received: 30 November 2015 / Accepted: 12 February 2016/Published online: 9 March 2016

(C) The Author(s) 2016. This article is published with open access at Springerlink.com

\begin{abstract}
The extracellular matrix (ECM) is one of the most important components within the tumor microenvironment that supports cancer development and metastasis. Under normal physiological conditions, the ECM is a tightly regulated network providing structural and biochemical support. However, the ECM becomes highly disorganized during neoplastic progression and consequently, stimulates cancer cell transformation, growth and spread. Cancer development and progression is also known to greatly benefit from the support of immune myeloid cells, which have multiple pro-tumorigenic functions including promoting tumor growth, migration and invasion, stimulating angiogenesis and suppressing anti-tumor responses. An increasing number of studies have shown that myeloid cells alter the ECM to support metastatic cancer progression and in turn, the ECM can influence the function of infiltrating myeloid cells. However, the exact nature of this relationship, such as the mechanisms employed and their molecular targets remains unclear. This review discusses evidence for the reciprocal dependence of myeloid cells and the tumor ECM for efficient tumor development and explores potential mechanisms involved in these interactions. A better understanding of this relationship has exciting implications for the development of new therapeutic treatments for metastatic cancer.
\end{abstract}

Su Yin Lim

esther.lim@mq.edu.au

1 Department of Oncology, CRUK/MRC Oxford Institute for Radiation Oncology, University of Oxford, Old Road Campus Research Building, Roosevelt Drive, Oxford OX3 7LJ, UK
Keywords Tumormicroenvironment $\cdot$ Myeloid cells $\cdot$ Cancer metastasis · Metalloproteinases $\cdot$ Cancer therapy $\cdot$ Immune cells

$\begin{array}{ll}\text { Abbreviations } \\ \text { ADAM } & \text { A disintegrin and metalloproteinase } \\ \text { CCL } & \text { chemokine (C-C motif) ligand } \\ \text { CXCL } & \text { chemokine (C-X-C motif) ligand } \\ \text { CD } & \text { cluster of differentiation } \\ \text { CSF } & \text { colony stimulating factor } \\ \text { EGF } & \text { epidermal growth factor } \\ \text { ECM } & \text { extracellular matrix } \\ \text { FGF } & \text { fibroblast growth factor } \\ \text { IL } & \text { interleukin } \\ \text { LOX } & \text { lysyl oxidase } \\ \text { M-CSF } & \text { macrophage colony-stimulating factor } \\ \text { MMP } & \text { matrix metalloproteinase } \\ \text { MDSCs } & \text { myeloid-derived suppressor cells } \\ \text { PI3 kinase } & \text { phosphoinositide 3-kinase } \\ \text { SNAI1 } & \text { Snail family zinc finger 1 } \\ \text { TIMP } & \text { tissue inhibitor of metalloproteinase } \\ \text { TGF } \beta & \text { transforming growth factor } \beta \\ \text { TAMs } & \text { tumor associated macrophages } \\ \text { TANs } & \text { tumor associated neutrophils } \\ \text { TNF } & \text { tumor necrosis factor } \\ \text { uPA } & \text { urokinase } \\ \text { VEGF } & \text { vascular endothelial growth factor } \\ \beta A P N & \beta \text {-aminopropionitrile }\end{array}$

\section{Introduction}

Cancer cells are dependent on a wide variety of supporting factors for their progression. In their landmark reviews, 
Hanahan and Weinberg proposed ten key hallmarks that are required by cancer cells for successful tumor development and metastasis $[1,2]$. Whilst the acquisition of oncogenes, the inhibition of tumor suppressor genes and other intrinsic genetic factors are key components of these hallmarks, it is becoming increasingly clear that tumor malignancy is also dependent on extrinsic factors involving interactions with stromal cells within the tumor microenvironment. Although these extrinsic factors are much less well understood, and may have little potential in inducing initial cancer cell transformation compared to intrinsic factors, the support from surrounding stromal cells have been shown to be indispensable for efficient metastatic progression [3].

The dependence of cancer cells on extrinsic factors for malignant progression was, and still is, an extremely exciting realization. Targeting genetic changes involved in initial cancer cell transformation is difficult and may not be a feasible therapeutic option. However, inhibiting tumor growth, and more importantly, suppressing the metastatic process may be attainable by targeting cancer-stromal cell interactions. Therapeutic strategies aimed at inhibiting and/or decreasing cancer metastasis is urgently required. As shown in studies conducted by Hayat et al. the survival rates of patients with new cancer diagnoses depend greatly on the initial cancer stage, with far lower survival rates associated with advanced metastatic disease [4]. Furthermore, a significant proportion of patients with new cancer diagnoses will advance to metastatic disease within 2 months and indeed, many patients already have detectable metastatic spread at the time of diagnosis. This only reinforces the need for selective therapeutic strategies to limit the development and progression of metastatic disease.

Amongst the stromal cells in the tumor microenvironment, immune myeloid cells have been reported to play key roles in the metastatic process. In this review, we first highlight the importance of myeloid cells in metastatic progression. Additionally, we discuss the role of the extracellular matrix (ECM), highlighting key proteins within this structure that play predominant functions in metastatic progression. Finally, we conclude by discussing the interaction and interdependence of myeloid cells and the ECM within the tumor microenvironment, and the potential of targeting myeloid cell-ECM interactions for therapy.

\section{The Metastatic Cascade and the Involvement of Myeloid Cells}

\section{The Metastatic Cascade}

Metastasis is a multistep process, greatly influenced by interactions between tumor cells and other cells and components of the tumor microenvironment $[5,6]$. After initial cancer cell transformation and tumor growth, cancer cells may leave the primary tumor site as a result of changes within the ECM and intravasate into the bloodstream or lymphatics. If the cancer cells survive in the circulation, they then arrest within distant organs (seeding) due to capillary size restriction and binding to coagulation factors. After extravasating into the tissues of the target organ, cancer cells will subsequently settle at pre-metastatic niches which provide the necessary factors to support the development of macrometastases and eventual colonization of the organ. Each step of the metastatic cascade is highly inefficient, reflecting the survival challenges cancer cells must overcome in order to establish distant metastases [7]. For example, many primary tumors succeed in shedding cancer cells into the circulation but only a few are able to avoid destruction by immune cells or death by anoikis [8] and indeed, an important measure of metastatic potential is the ability of cancer cells to survive outside the tumor microenvironment.

\section{Immune Myeloid Cells in Cancer}

Numerous studies now point to immune cells being one of the most influential factors in stimulating the malignant potential of tumor cells; those of the myeloid lineage appear to be amongst the most important contributors. Immune myeloid cells consist of three main groups of terminally differentiated cells; granulocytes, monocytes/macrophages and dendritic cells, with the granulocytes being further divided into neutrophils, eosinophils, mast cells and basophils. Granulocytes are responsible for releasing a variety of cytokines to mediate inflammatory processes in response to infection and injury. Neutrophils, in particular, have a central role in being able to phagocytose invading pathogen [9]. Similar to neutrophils, monocytes are recruited to sites of inflammation and differentiate into macrophages in order to phagocytose pathogens, apoptotic cells and also mediate tissue repair [10]. Dendritic cells, as prototypic antigen presenting cells that process foreign antigens, bridge the gap between innate and adaptive immunity by priming the humoral and adaptive immune responses [11]. All these cell types are indispensable for the full functioning of an immune system.

It is becoming clear that within the tumor microenvironment, the normal functions of myeloid cells are changed [12]. Numerous studies have shown that the tumor microenvironment preferentially polarizes myeloid cells into tumor-supporting phenotypes such as the myeloid-derived suppressor cells (MDSCs) to suppress cytotoxic immune responses and promote cancer progression. Abnormal dendritic cell myelopoiesis and abnormal dendritic cell function within the tumor microenvironment also contribute to the inability to recruit potent cytotoxic immune responses against tumors [13, 14]. Macrophages are also known to exhibit cancer-promoting activity, leading to their designation as tumor-associated 
macrophages (TAMs) $[15,16]$. Studies have demonstrated that TAMs shift away from the M1 "activated" phenotype which is highly tumoricidal, towards the M2 "alternatively activated" phenotype thought to be important for immunomodulation, tissue repair and supportive of cancer progression [17]. TAMs do not produce IL-12 and consequently, do not recruit the cytotoxic responses of natural killer and $\mathrm{T}_{\mathrm{H}} 1$ cells. Instead, they produce IL-10, driving the polarization of $\mathrm{T}_{\mathrm{H}} 2$ responses, which instead support cancer progression. TAMs also produce CCL22, which recruits immunosuppressive $\mathrm{T}$ regulatory cells that inhibit $\mathrm{T}$ cell activation [18]. In addition to TAMs, tumor-associated neutrophils (TANs) have also been described [19]. Fridlender et al. showed that TGF $\beta$ signaling within the tumor was responsible for inducing a population of N2 "pro-tumor" TANs instead of N1 "anti-tumor" TANs [20]. N2 TANs produce low levels of inflammatory cytokines, do not potently activate cytotoxic $\mathrm{CD} 8^{+} \mathrm{T}$ cells and also produce large amounts of arginase, which inhibits T cell responses [21]. Again, these results demonstrate the ability of tumors to abrogate anti-tumor responses by altering myeloid cell functions to create a supportive environment for growth. Altogether, these findings point to supportive roles for most myeloid cells in tumor growth and metastasis within the tumor microenvironment [22, 23].

\section{Immune Myeloid Cells during Cancer Metastasis}

Myeloid cells have been shown to favor many steps of the metastatic cascade, including cancer cell intravasation, extravasation from the blood, and arrest in distant organs [15, 24, 25]. During intravasation, cancer cells associate with TAMs via EGF-CSF1 signaling to facilitate this process [26]. Once in the circulation, cancer cells are subjected to destruction from the shear force of the circulation as well as from patrolling immune cells. In response, tumor cells and myeloid cells produce osteopontin which protects tumor cells from apoptosis $[27,28]$. In addition, cancer cells are able to circumvent eradication by associating with fibrin clots and blood platelets, which helps protect against shear stress and shields cancer cells from immune targeting. Formation of these aggregates also facilitates trapping of cancer cells in small vessels and capillaries, leading to their arrest and adhesion to the endothelium [5]. Circulating cancer cells employ similar mechanisms as immune cells, involving selectins, integrins and cell adhesion molecules, for adhesion to the vascular endothelium. Following adhesion, cancer cells extravasate out of the circulation, likely with the aid of TAMs [29] in a manner similar to intravasation.

Myeloid cells are also able to support metastatic outgrowth once secondary implantation has taken place. Stromal and cancer cells of the tumor microenvironment upregulate a wide range of chemokines and other chemoattractants including CCL2, CCL5, CXCL12, M-CSF, VEGF and TGF $\beta$ in order to recruit myeloid cells [24, 30-32]. In addition, hypoxia resulting from ischemic areas of the tumor can induce chemoattractants that stimulate myeloid cell recruitment [33]. Once recruited into the tumor microenvironment, myeloid cells upregulate a number of different growth factors such as EGF, FGF2 and platelet-derived growth factor to promote cancer growth and progression [34, 35]. Aside from promoting myeloid cell recruitment, hypoxia is also important in enhancing growth factor expression by myeloid cells [35].

Although recruitment of myeloid cells to actively growing tumors is undoubtedly important to support further progression, a number of studies have demonstrated that myeloid cell recruitment to metastatic sites is equally important for cancer cell implantation. This early recruitment allows myeloid cells to create an environment optimized for rapid development of macrometastases, also known as the "pre-metastatic niche" [36]. Myeloid cells were found to aggregate at sites of liver metastases and the prevention of their recruitment hindered metastasis foci expansion, decreased tumor burden and prolonged the survival of tumor bearing mice [37, 38]. Kaplan et al. showed that VEGFR $1^{+}$myeloid cells were recruited to pre-metastatic lung sites before metastatic spread and the removal of these myeloid cells prevented cluster formation and tumor metastasis [39].

Numerous studies have aimed to elucidate the mechanisms employed by myeloid cells to create a pre-metastatic niche once they have been recruited to secondary sites. One mechanism is the stimulation of angiogenesis, mediated through the production of numerous factors including VEGF, basic FGF, $\mathrm{TNF} \alpha$ and numerous MMPs known to support angiogenesis $[33,40]$. In addition, it is thought that MDSCs are able to differentiate into endothelial cells and directly contribute to the formation of vascular networks. Another key mechanism in the establishment of the pre-metastatic niche is the suppression of anti-tumor responses, which will prevent the destruction of newly implanted cancer cells before they have a chance to expand. As mentioned previously, the phenotypes of myeloid cells within the tumor are altered to be more permissive and even supportive of cancer progression. In addition to osteopontin expressed by tumor cells, MDSCs within the tumor microenvironment are also capable of producing osteopontin [27]. The upregulation of osteopontin increases the immunosuppressive activity of MDSCs and increases recruitment of $\mathrm{T}$ regulatory cells, thus creating an immunosuppressive microenvironment to support metastatic cancer progression. Also, MDSCs are known to generate oxidative stress in the tumor microenvironment through the production of reactive oxygen species, resulting in impaired T cell activation and function [12]. Finally, a more recently reported role is the ability of myeloid cells to remodel various components of the tissue microenvironment to assist further cancer development; this is discussed in more detail in subsequent sections of the review. Consistent with all these findings, Bingle et al. 
reported that myeloid cell density in tumors correlated with poor prognosis and that metastatic cancer progression is suppressed in the absence of myeloid cells, strongly suggesting that survival of patients with metastatic disease would be significantly improved by preventing myeloid cell recruitment to tumors [41].

\section{The Extracellular Matrix and Its Role in the Tumor Microenvironment}

The ECM, consisting of a complex network of proteins, glycoproteins, proteoglycans and polysaccharides, is a critical part of the normal tissue environment that provides structural and biochemical support to surrounding cells [42]. Under normal physiological conditions, the components of the ECM undergo a constant cycle of synthesis, deposition, remodeling and degradation, all of which contribute to ECM stiffness, elasticity and function. Deposition of new ECM components is mediated largely by fibroblasts, whereas ECM remodeling and degradation is regulated by a variety of proteolytic enzymes (Fig. 1a) [43]. Due to their dynamic nature and biochemical diversity, the ECM can regulate almost all aspects of cellular behavior and communication through its interaction with cell surface receptors such as integrins [44]. Overall, the reciprocal interaction between the ECM and cells of the surrounding stroma is essential to allow rapid adaptation of tissues to environmental stimuli. Importantly, this makes the alteration of ECM components and biodynamics an effective way to regulate cellular behavior and functions.

The ECM is a significant player in metastatic cancer progression $[45,46]$ and the dependence of ECM support for both early tumor development and late-stage malignant progression has been demonstrated in several studies [47, 48]. Compared to normal ECM, the ECM within the tumor microenvironment is highly transformed, disorganized and deregulated. Alterations in the composition of the tumor ECM are attributed to overexpression of certain ECM components and their receptors by cancer cells and stromal cells including endothelial cells, fibroblasts and immune cells [49, 50]. ECM stiffness and architectural properties are also altered due to the overexpression of ECM remodeling enzymes such as the lysyl oxidase (LOX) family of enzymes [51]. These biochemical and structural changes in the ECM can influence cell behavior and interactions, which may lead to malignant transformation and metastatic spread (Fig. 1b-d) [52, 53].

Certain ECM components can facilitate the metastatic process by stimulating cell adhesion, attachment and motility [ 42 , 54]. For example, in exposed patches of the basement membrane, laminins promote the attachment of metastatic cancer cells to collagen IV, in order to mediate their arrest and the establishment of early metastatic colonies $[55,56]$. Culture of cancer cells on collagen IV/laminin matrices also increased the migration rates of several cancer cell lines [57]. In particular, Koshikawa et al. demonstrated that cancer cells in the presence of laminin-5 upregulated MMP14 expression, which correlated with cancer cell migration [58]. The interaction between cancer cells and abnormal collagen scaffolds at the invasion fronts of tumors has also been shown to promote cancer cell invasion [59-61]. Changes in the stiffness and elasticity of the ECM will also have significant effects since they are detected by surrounding cells [62, 63]. For example, distortion of cellular shape and orientation affect the spatial distribution of integrins expressed by surrounding cells and consequently, affects integrin-mediated signaling [44]. In support of this, Levental et al. demonstrated that collagen cross-linking and the resultant increase in ECM stiffness initiated PI3 kinase signaling cascade to promote oncogenic transformation [64]. In addition, Paszek et al. found that increased collagen deposition and increased ECM stiffness upregulated integrin signaling, which activated focal adhesion kinases and consequently, promoted cancer cell survival, growth and migration $[65,66]$.

After cancer cell implantation (Fig. 1c), increased ECM deposition within the tumor microenvironment and in the pre-metastatic niche (Fig. 1b) may promote cancer cell survival through the prevention of anoikis. Apoptosis through the anoikis signaling pathway is one of the many challenges cancer cells must overcome during the metastatic process [8]. These signaling pathways are prevented by successful adherence to the ECM, thus increased ECM deposition is likely to aid cancer cell survival. In support of this, growing pancreatic cancer cells on collagen IV matrices has been reported to confer apoptosis resistance, as well as stimulating their growth and migration [67].

Changes in the ECM can also affect other aspects of the metastatic process. For example, laminin is a major constituent of the basement membrane [68], which is essential in supporting the endothelium of blood vessels [69, 70], and has been shown to indirectly support angiogenesis by promoting endothelial cell survival and function [71, 72]. The development of new vasculature also promotes cancer cell metastasis by providing additional routes by which cancer cells can leave the tumor [73]. This is reflected in studies which found that tumor vascularization correlated with metastasis incidence and reduced patient survival in a range of cancers $[74$, 75].

Collectively, these studies indicate that abnormal ECM composition and dynamics within the tumor microenvironment are essential for cancer development, by accelerating the growth of primary tumors, their spread to distant sites and eventually, the growth of new metastatic colonies. In the following sections, we review several key ECM regulators and discuss how their alteration and deregulation can contribute to cancer malignancy. 


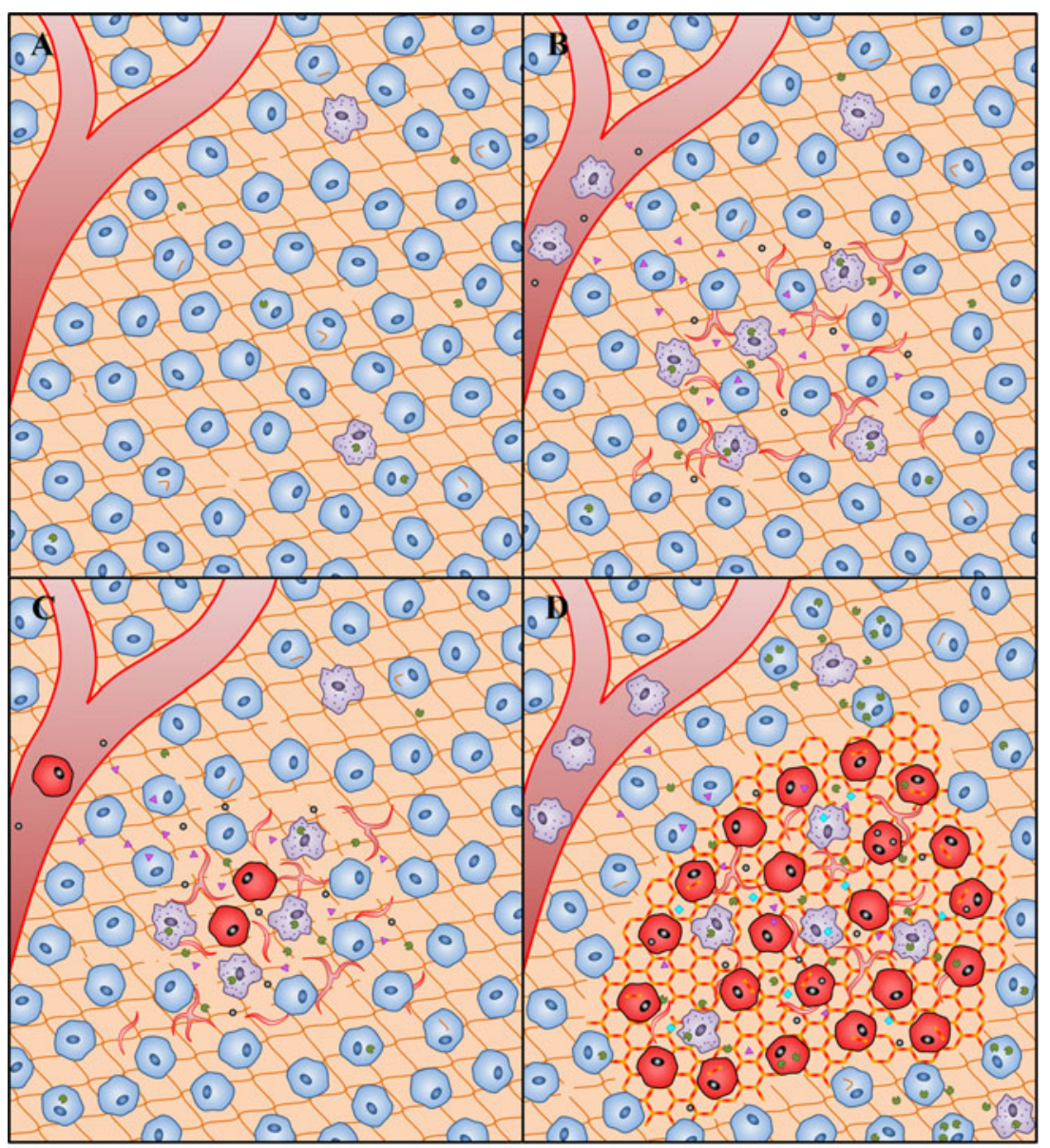

\section{Key}

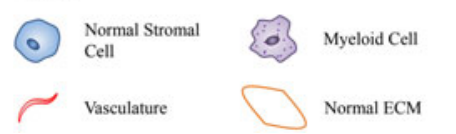

$\rightleftharpoons$ Vasculature

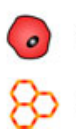

Cancer Cell

Tumor ECM

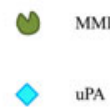

○ LOX

$\nabla \quad$ Chemokines
Fig. 1 The coordination of myeloid cells and the ECM during cancer progression and metastasis. a In the normal tissue environment, physiological levels of ECM regulating enzymes maintain ECM biodynamics to support normal tissue function. In this environment, normal stromal cells comprise a wide variety of cell types including fibroblasts, pericytes and immune cells. b During cancer progression, ECM regulating enzymes such as MMPs and LOX are upregulated by cancer cells and aggregate at the pre-metastatic niche where they remodel the ECM. Chemokines produced locally at the pre-metastatic site together with MMPs and LOX promote the recruitment of myeloid cells. The recruited myeloid cells produce angiogenic molecules to establish a rich vascular network. c Cancer cells spread from the primary tumor and implant at the pre-metastatic niche. The supply from the rich vascular network and pro-tumorigenic factors produced by myeloid cells stimulate metastatic outgrowth. Upregulated expression and activity of ECM regulating enzymes also contribute to altered ECM and tumor growth. d Myeloid cells produce growth factors and angiogenic molecules to ensure continual tumor expansion. ECM regulating enzymes including MMPs, LOX and UPA are upregulated by cancer and myeloid cells, resulting in altered and remodeled tumor ECM that is highly supportive of tumor expansion

\section{The Matrix Metalloproteinases (MMPs)}

A large number of enzymes are responsible for regulating ECM biodynamics and their known roles in cancer progression are summarized in Table 1. Matrix metalloproteinases (MMPs) represent the most abundant ECM regulator within the tissue microenvironment [53, 76]. MMPs cleave ECM components at specific sites in order to regulate ECM availability and biodynamics. MMPs also indirectly regulate cellular behavior by exposing cryptic sites within ECM components that have separate biological functions, and by releasing important signaling molecules stored within the ECM network [77, 78]. Several mechanisms mediate MMP function, including transcriptional regulation, production as inactive precursors, selective distribution and the action of endogenous MMP activators and inhibitors within tissues. However, during malignant progression, MMP activity becomes deregulated, which contributes toward the disruption of 
Table 1 Key ECM regulating enzymes and their roles in metastatic cancer progression

ECM regulating Roles/effects in metastatic cancer progression

References

enzyme

\section{MMPs}

MMP1

MMP2

MMP7

MMP8

MMP9

MMP11

MMP12

MMP14

TIMPs

TIMP1

TIMP2

\section{LOX Family}

LOX

LOXL2

LOXL4

uPA

uPA

ADAMs

ADAM8

ADAM9

ADAM10

ADAM12

ADAM15

ADAM17
Increased expression associated with increased cellular susceptibility for tumorigenesis. After initial tumor development, MMP1 is likely to support cancer cell invasion and the formation of distant metastases.

Important roles in supporting tumor angiogenesis through the promotion of epithelial cell migration. Increased expression has also been identified as a marker for enhanced tumor progression and poor patient outcome.

Important role in supporting carcinogenesis and initial tumor development. Increased expression is also associated with increased invasive and malignant potential.

Responsible for mediating myeloid cell recruitment to tumors, as well as protecting tumor cells from apoptosis and chemotherapy. Expression is associated with poor outcome in patients.

Demonstrated to have protective roles by impairing cancer progression, including inhibition of cancer cell $[103,166,167]$ transformation and metastatic spread.

Important roles in tumor angiogenesis and vasculogenesis. Increased expression is also associated with myeloid cell recruitment, cancer cell intravasation and reduced patient survival.

Increased expression associated with faster cancer progression and decreased patient survival.

Increased expression associated with impaired cancer progression and improved survival in patients.

Numerous roles including the regulation of epithelial cell migration, vascular stability and regulating cancer cell migration and invasive potential.

Demonstrated to have both anti-tumor and pro-tumor functions. Anti-tumor functions include the suppression of tumor growth and angiogenesis. Pro-tumor functions include the promotion of tumor growth, recruitment of cancer associated fibroblasts and the promotion of pre-metastatic niche formation. Expression levels also correlate with poor patient survival.

Demonstrated to have both anti-tumor and pro-tumor functions. Anti-tumor functions include the impairment of tumor angiogenesis and invasion. Pro-tumor functions include the promotion of apoptosis resistance in tumor cells and promotion of metastatic spread.

Numerous roles in supporting the metastatic cascade, including the promotion of an invasive phenotype in cancer cells, formation of the pre-metastatic niche and increased metastatic spread. Known to increase the stiffness of the ECM and to support cancer progression.

Increased expression associated with increased invasive potential, metastatic spread and poor patient outcome. Also shown to be essential for developing a microenvironment supportive of cancer progression.

Upregulated in cancer cells and linked to increased metastatic potential.

Shown to have an important role in promoting the metastatic potential of cancer cells through increased tumor angiogenesis and cancer cell intravasation. Expression also associated with decreased patient survival.

Upregulated in cancer cells and linked to increased invasive behavior and reduced patient survival.

$[129,190]$

Important roles in supporting tumorigenesis and the generation of poorly differentiated tumors. Expression is also associated with increased invasive and metastatic potential of cancer cells, and reduced patient survival.

Shown to regulate E-cadherin function, promote carcinogenesis, cancer cell proliferation and protection against apoptosis.

Known to support cancer progression by promoting cancer cell growth and conferring resistance to apoptosis.

Upregulated at the invasion front of tumors and correlates with metastatic progression.

$[125,127,128,191$, 192]

$[124,193,194]$

$[126,195,196]$

[197, 198]

Increased expression associated with increased invasive behavior, faster progression and poorer outcome [199-201] in patients. normal tissue ECM, and also the abnormal regulation of several signaling pathways $[79,80]$.

Numerous studies have demonstrated that MMP overexpression is a common feature across various cancers
[81-84]. MMP is upregulated by a variety of stromal and cancer cells within the tumor microenvironment $[80,85,86]$. Some of the first evidence for the pro-tumor roles of MMPs came from early MMP ablation studies in animal models. 
Using a mouse model, Kim et al. demonstrated that MMP9expressing cancer cells were capable of entering the bloodstream, and their inhibition using the MMP inhibitor marimastat reduced cancer cell intravasation by over $90 \%$ [87]. Consistent with these findings, other studies showed that MMP9 deficient mice developed significantly fewer metastatic colonies compared to wild-type mice following cancer cell inoculation [88]. Perhaps most convincingly, the reduced capacity of MMP9 deficient mice to develop metastatic colonies was reversed with the transplant of MMP9-expressing bone marrow-derived cells [89]. Together, these studies demonstrate that both tumor and stromal-derived MMP9 are necessary for successful metastatic tumor development. Further evidence supporting the importance of MMP function in metastatic cancer progression comes from clinical studies, showing elevated MMP expression correlating with poor prognosis in almost all forms of cancer [84]. For example, the expression of MMP9, MMP13 and MMP14 all correlated with poor survival in patients with breast cancer [90-92], and expression of MMP1 and MMP2 was associated with highly aggressive breast cancer that metastasizes rapidly to the lung [93].

Recent studies have begun to elucidate how MMPs support metastatic cancer development $[78,79]$ and it is becoming increasingly clear that MMPs have pleiotropic roles and effects on both tumor and stromal cells. For example, MMP2 and MMP9 were upregulated in pre-cancerous nodules where they promoted a switch to an angiogenic phenotype, resulting in tumor transformation and growth [94, 95]. Correspondingly, inhibition of MMP2 and MMP9 using the SB-3CT inhibitor reduced the incidence of liver metastasis and increased the survival of mice with $\mathrm{T}$ cell lymphoma [96]. Another interesting insight into MMP function within tumors was reported by Sternlicht et al. who found that induction of MMP3 expression in mammary epithelial cells facilitated the formation of mesenchymal-like tumors [97]. This epithelial to mesenchymal transition of cancer cells is an early phenotypic change associated with aggressive cancer development [98]. However, the tumors grew independent of MMP3 expression after initial formation, suggesting that MMP3 is important during initial tumor development. In support of this, MMP3 overexpressing transgenic mice developed spontaneous pre-malignant lesions and mammary cancers despite the lack of carcinogens or pre-existing gene mutations, indicating that abnormal MMP3 activity is sufficient to initiate cancer cell transformation [97].

MMPs also cleave certain ECM components to expose functional cryptic sites that may be pro-tumorigenic [99]. MMP2 and MMP14 have been shown to cleave the laminin-5 $\gamma 2$ chain to expose cryptic sites capable of inducing epithelial cell migration [100]. Petitclerc et al. demonstrated that upon cleavage, collagen acts as a ligand for the $\alpha_{\mathrm{V}} \beta_{3}$ integrin expressed on malignant melanoma cells and the resultant interaction promoted the survival and growth of melanoma cells [101]. Furthermore, other studies found that cleavage of collagen IV by MMPs exposed a cryptic site that promoted angiogenesis and tumor growth in CS1 melanoma and HT1080 human fibrosarcoma cells [102]. Taken together, MMPs have multiple roles in supporting tumor development and progression, including facilitating initial tumor formation, promoting tumor angiogenesis and cancer cell motility.

Although the majority of MMPs appear to have pro-tumorigenic functions within the tumor microenvironment, it is important to note that some MMPs may have anti-tumor roles. In a mouse model of chemical carcinogenesis, the incidence of skin papillomas and fibrosarcomas was greater in MMP8 deficient mice compared to wild-type, and could be reversed by transplanting MMP8-expressing hematopoietic cells, suggesting that MMP8 has protective effects against cancer transformation and growth [103]. Similar protective roles have been reported for MMP3; Witty et al. demonstrated that MMP3 overexpression reduced the incidence of chemical-induced skin carcinomas following carcinogen treatment [104]. Interestingly, Takeha et al. showed that the number of MMP9-expressing macrophages along the infiltrating margin of tumors was inversely associated with the incidence of liver metastasis and an infiltrating growth pattern in colorectal cancer [105]. This suggests that MMP9 may also have protective effects in contrast to its role in promoting cancer cell transformation and initial tumor development. In support of an anti-tumor role for MMPs, treatment with the MMP inhibitor tanomastat, which has selective activity against MMP2, MMP3 and MMP9, was shown to lead to a worse outcome compared to standard treatments [106]. Collectively, these results indicate that certain MMPs may have additional anti-tumor functions although the exact mechanisms of MMP-mediated anti-tumor effects are still unclear. One possible mechanism may depend on the ability of MMPs to generate the angiogenesis inhibitors angiostatin and endostatin within tumors, which can inhibit the proliferation of endothelial cells and prevent the "angiogenic switch" required for efficient tumor development [107, 108].

It is clear that MMPs have far more complex roles within the tumor than first thought. Numerous studies have now demonstrated that MMPs are able to both support and inhibit primary tumor development and subsequent metastasis. In some instances, such as in the case of MMP9, the same enzyme is able to produce opposite effects. This discrepancy may be due to differences in function and expression of different MMP types, and has important implications for the use of MMP inhibitors to treat metastatic cancer, since broad spectrum inhibition of MMPs will ablate both anti-tumor and pro-tumor functions. Further studies are needed to determine which MMPs are polarized towards supporting metastatic cancer progression and what factors determine the tumor-promoting functions of MMPs. 


\section{Tissue Inhibitor of Metalloproteinases (TIMPs)}

Although MMPs clearly play an essential role in cancer metastasis, other groups of ECM regulators including the tissue inhibitor of metalloproteinases (TIMPs) also have important influences on metastatic progression [109]. Thus far, four members of TIMPs have been identified, each containing an $\mathrm{N}$ terminal domain that slots into the active site of MMPs, analogous to an MMP substrate, which then inhibits MMP activity. Each TIMP family member may have selective inhibitory properties. For example, TIMP2 and TIMP3 are particularly effective at inhibiting membrane-bound MMPs. TIMPs have been shown to influence metastatic cancer progression, mainly through inhibiting MMP activity. Buck et al. demonstrated that high levels of circulating TIMP1 impaired chemical-induced carcinogenesis and consequently, cancer progression [110]. Consistent with this, Ikenaka et al. used a TIMP1 transgenic mouse model to demonstrate that high TIMP1 expression suppressed tumor growth and angiogenesis [111]. These results demonstrate protective functions of TIMPs against cancer progression. However, similar to MMPs, TIMPs have also been shown to mediate pro-tumor functions. High stromal levels of TIMP1 in human cancers were found to promote cancer growth, promote the recruitment of cancer associated fibroblasts and accelerate cancer progression [112]. This is in keeping with elevated TIMP1 and TIMP2 expression in human cancers and their correlation with poorer prognosis $[84,113]$. Hence, similar to the MMPs, TIMPs have opposing effects in cancer progression and further work is required to elucidate the factors and mechanisms influencing TIMP function within the tumor microenvironment.

\section{Lysyl Oxidase (LOX)}

The lysyl oxidase (LOX) family is another group of ECM regulating enzymes with important influences on ECM biodynamics. The LOX family currently consists of 5 members of copper-dependent amine oxidases that are expressed by stromal cells in pre-malignant tissues. LOXs mediate cross-linking between collagens and elastin to increase ECM stiffness and consequently, its capacity to support tumor growth and invasion [51, 64, 114]. LOXs are overexpressed in a variety of cancers and are shown to be markers of increased metastasis, progression and reduced patient survival $[64,115]$. Kirschmann et al. observed LOX expression in breast cancer cells with highly malignant phenotypes and inhibition of its function significantly decreased invasive capacity, suggesting a role in tumor cell invasion [116]. Peinado et al. demonstrated that LOXL2 and LOXL3 interacted with SNAI1 to induce epithelial to mesenchymal transition, and knockdown of LOXL2 alone decreased tumor growth and reduced invasive and angiogenic markers within the tumors
[117]. In keeping with this finding, Barker et al. showed that LOXL2 promoted metastatic spread through the upregulation of MMP9 and TIMP1 expression [118]. LOX-mediated cross-linking of the ECM has also been shown to promote tumor progression by enhancing integrin signaling, which can inhibit cancer cell apoptosis, regulate cancer stem cell function and growth factor signaling [44]. Taken together, these results indicate that LOX proteins have multiple pro-tumorigenic effects and suggest that their inhibition could be a potential strategy to impair cancer progression and improve patient outcome.

\section{Urokinase (uPA)}

Similar to the LOX proteins, urokinase (uPA) has also been shown to have key functions in tumor progression [119]. uPA is a serine protease forming a critical component of the urokinase-type plasminogen activator system and responsible for the generation of plasmin, an enzyme capable of degrading most ECM proteins. The importance of uPA is highlighted in studies demonstrating its association as a prognostic marker in patients with cancer. Weigelt et al. found that higher levels of uPA activity correlated with a more aggressive phenotype in metastatic breast cancer [120]. Similarly, Shiomi et al. demonstrated that elevated expression of uPA predicted the invasive behavior of esophageal cancer and also correlated with patient survival [121]. In support of uPA's role in tumor progression, Kim et al. demonstrated that in the absence of surface UPA, cancer cells were incapable of intravasation, despite high expression levels of MMP9 [87]. A possible cooperation between UPA and MMP9 is reflected in the dependence of plasmin, generated by uPA, for the activation of latent MMPs within tissues. This is an exciting prospect, as it suggests that the pharmacological inhibition of uPA may suppress pro-tumor functions of both UPA and certain MMPs such as MMP9. Equally however, the uncertainties surrounding the functions of MMP9 within the tumor microenvironment mean that inhibition of uPA may instead support cancer progression.

\section{A Disintegrin and Metalloproteinase (ADAM) family}

Another group of ECM-regulating enzymes important in metastatic cancer progression is the ADAM proteins, a disintegrin and metalloproteinase family of transmembrane and secreted enzymes $[122,123]$. These enzymes are closely related to the MMPs and serve a wide range of functions including cell migration, cell fate determination and regulation of immune responses. Although all ADAMs contain a metalloproteinase domain, only 13 of the 21 members expressed in humans exhibit proteolytic activity on the ECM, suggesting that the remaining 8 may have alternate functions aside from proteolysis. Some members of the ADAM family have been implicated in metastatic cancer progression. Maretzky et al. showed 
that ADAM10, similar to MMP3, was able to induce epithelial to mesenchymal transition of tumor cells through the cleavage of E-cadherin [124]. These results suggest that ADAM10 may be important for initial tumor development and the acquisition of aggressive metastatic behavior. Mazzocca et al. demonstrated that a secreted form of ADAM9 was able to promote cancer cell invasion by binding the $\alpha 6 \beta 4$ and $\alpha 2 \beta 1$ integrins [125]. ADAM12 has also been shown to protect against breast cancer cell apoptosis [126]. Overall, these findings indicate that certain ADAM proteins are important for metastatic initiation and progression. In support of these experimental studies, clinical data demonstrated that the expression of ADAM8 and ADAM9 associated with increased metastatic spread and reduced patient survival in a range of cancers [127-129]. Hence, certain members of the ADAM family may represent attractive targets in impairing metastatic cancer progression.

\section{Myeloid Cells and Their Relationship with the ECM-Regulating Enzymes}

Tumor-associated myeloid cells are essential for efficient primary tumor development and metastatic spread. However, very little is known about how myeloid cells are able to promote metastatic progression. Given that efficient metastatic spread and growth is heavily reliant on the tumor ECM, it is likely that myeloid cells mediate the biodynamics and functions of the ECM within the tumor microenvironment as a potential mechanism to promote cancer development. In turn, tumor ECM may be able to influence the functions of infiltrating myeloid cells. In the following sections, we discuss a growing body of evidence supporting a reciprocal relationship between myeloid cells and the tumor ECM in supporting metastatic cancer progression; these interactions are summarized in Fig. 2.

Myeloid cells may regulate ECM function and the consequent effects on malignant progression via direct production of ECM regulating enzymes. Infiltrating myeloid cells express MMPs, and whilst cancer cells and other stromal cells also contribute to MMP expression within the tumor microenvironment, myeloid cells are the predominant source of MMPs in a range of invasive cancers including breast, bladder and ovarian carcinomas [130-132]. Using a transgenic mouse model of skin cancer, Coussens et al. showed that transplantation of MMP9-expressing hematopoietic cells can reverse the impaired development of metastatic cancer in MMP9 null mice [89]. Hence, MMP9 expression by infiltrating hematopoietic cells is sufficient to instigate metastatic growth. Additionally, primary tumors induced MMP9 expression in lung macrophages, which consequently promoted lung metastasis [133]. Ardi et al. also demonstrated that MMP9 expressed by neutrophils may be more readily activated to stimulate angiogenesis [134]. Altogether, these studies demonstrate the importance of MMPs expressed by infiltrating myeloid cells for cancer progression, and suggest that inhibition of myeloid cell recruitment, or inhibition of myeloid cell-derived MMP may inhibit cancer metastasis. Similar to the MMPs, uPA is also predominantly synthesized by tumor-associated macrophages in a number of different cancers [135, 136], and increased uPA expression in tumor-associated macrophages correlated with relapse incidence and decreased survival in patients with breast carcinomas [137].

Whilst myeloid cells may express MMPs to promote malignant progression, MMPs themselves can influence myeloid cell function, suggesting a reciprocal relationship. MMP7 and MMP9 induced syndecan 1 and CXCL6 production in tumor
Fig. 2 The cooperative relationship between myeloid and cancer cells, and the ECM in support of cancer progression. Myeloid and cancer cells produce ECM regulating enzymes such as MMPs, LOX and uPA to alter the tumor ECM. In turn, the tumor ECM mediates function of the myeloid and cancer cells, creating a complex and interdependent relationship that favors cancer progression and metastatic development

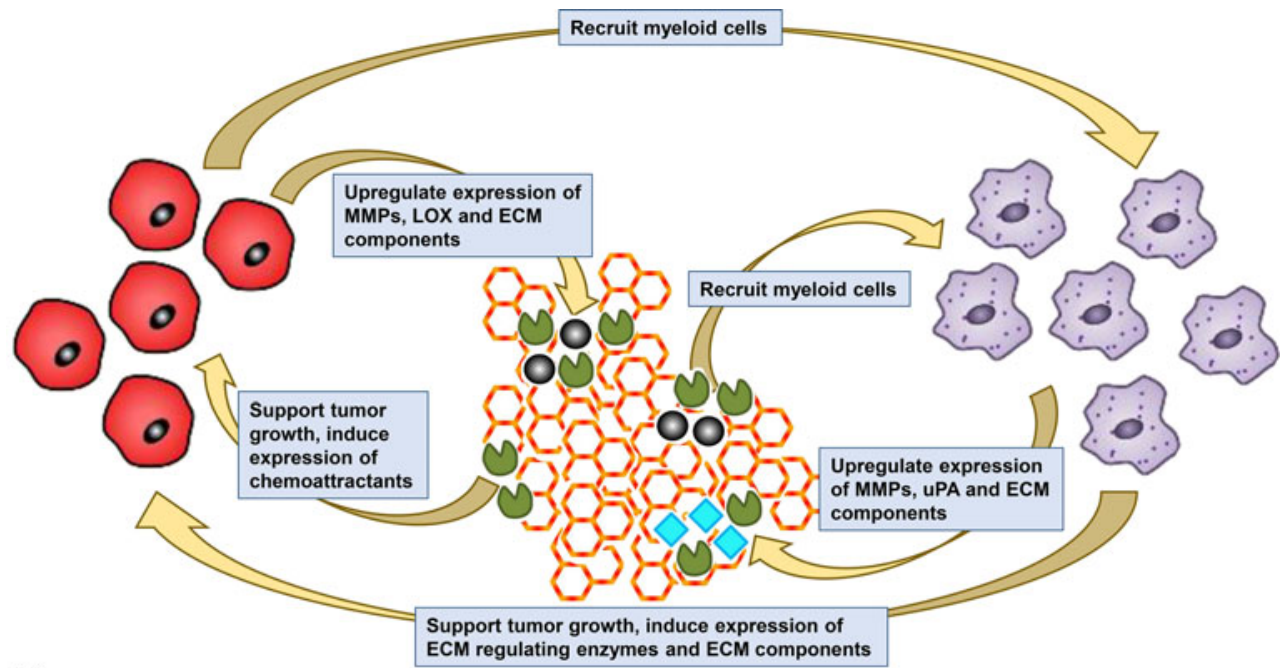

Key

Myeloid Cell 
cells, which act as chemoattractants for neutrophils and mediate their influx to the tumor microenvironment $[138,139]$. Similarly, MMP3 has also been shown to function as a chemoattractant for macrophages [140]. These studies suggest a positive feedback loop between MMP expression and myeloid cell recruitment, where the expression of MMPs by myeloid cells may stimulate additional recruitment and ultimately, increase the efficiency of metastatic cancer progression. Similarly, LOX proteins expressed by cancer cells accumulate at potential metastatic sites, where they mediate collagen IV crosslinking, which in turn, triggers the recruitment of hematopoietic cells to form the pre-metastatic niche [141].

Although myeloid cell-derived expression of ECM regulating enzymes is important in supporting tumor progression, it is likely that myeloid cells employ other mechanisms to contribute to the deregulated ECM dynamics observed within tumors. In keeping with this, we recently found that depletion of CD11 $\mathrm{b}^{+}$myeloid cells in a mouse model of colorectal cancer liver metastasis significantly decreased expression of collagen and laminin isoforms by cancer cells, suggesting that myeloid cells may regulate expression and deposition of certain ECM components via effects on cancer cells [142]. However, we cannot exclude the possibility that myeloid cells themselves can produce and deposit additional ECM components in the same setting. Evidence in support of this comes from studies on Kupffer cells, the main population of myeloid cells within the liver. Kupffer cells are known to have important anti-tumor functions, with numerous studies having demonstrated their ability to clear circulating and dormant metastatic cells residing in the liver, thus reducing the incidence of liver metastasis [143]. However, Kupffer cells also have pro-tumorigenic effects during liver metastasis [143, 144]. Kupffer cells are known to produce a number of different ECM components [145], which may contribute to their ability to assist metastatic colonization of the liver. Another possibility to consider is that infiltrating myeloid cells may induce abnormal ECM expression and deposition by surrounding stromal cells such as cancer-associated fibroblasts, which have been shown to produce high levels of ECM molecules within tumors [50].

The increased ECM deposition induced by myeloid cells may have many important implications. As mentioned earlier, myeloid cells are recruited to sites of metastasis spread or pre-metastatic sites and are essential for efficient metastatic foci expansion and development [37-39]. Given the importance of a deregulated ECM for cancer progression, it is likely that myeloid cells contribute to abnormal ECM expression and structure to form a suitable pre-metastatic niche and/or a hospitable tumor microenvironment as illustrated in Fig. $1 \mathrm{~b}$. Many cancer cells implant at secondary sites only to remain dormant for years and fail to establish macrometastases [146]. Myeloid cell recruitment and consequent distortion of ECM composition and dynamics could be a mechanism to transform an otherwise dormant tumor into one capable of forming macrometastases.

\section{Inhibition of Tumor ECM for Therapeutic Treatments}

To date, there has been little progress in developing therapeutic agents to reverse or prevent changes that occur in the ECM during cancer progression. Given the evidence supporting a key role for MMPs in promoting metastatic cancer development, these ECM regulating enzymes were considered attractive therapeutic targets. However, numerous MMP inhibitors including marimastat and tanomastat have performed disappointingly in clinical trials $[106,147,148]$. Patients showed no change in overall survival when administered these MMP inhibitors. However, it is too early to conclude that MMPs are not suitable targets and there are a number of reasons that could explain their ineffectiveness. One major concern was whether the doses used were high enough to inhibit MMP activity [106]. It was proposed that patients who developed musculoskeletal symptoms were the only ones to have received a dose high enough to inhibit MMP activity. King et al. found that patients who were given the MMP inhibitor marimastat developed musculoskeletal side effects but had a significantly higher survival time compared to patients who were given marimastat but developed no side effects [149]. Another important argument is that MMP inhibitors were tested in cases when metastatic spread was too far advanced to show any therapeutic benefit. The findings that MMPs may have important roles in promoting early tumor initiation and development [97] implied that MMP inhibition will be far more successful in patients with early metastatic disease. A further criticism is that previous MMP inhibitor trials did not account for the fact that certain MMPs are clearly more important in supporting cancer progression compared to others. The majority of MMP inhibitor agents used had non-specific, broad spectrum activity against a variety of different MMPs. From the experimental studies discussed in this review, it is clear that MMP3 and MMP9 play particularly important roles in supporting metastatic cancer progression and may account for the greater part of MMP-mediated pro-tumor functions. Selective inhibition of MMP3 and MMP9 may minimize the inhibition of anti-tumor functions amongst other MMPs. More promising results from MMP inhibition clinical trials may be achieved by ensuring an adequate dosage for complete MMP inhibition, as well as selectively inhibiting MMPs with protumor functions.

Numerous studies have also demonstrated that the inhibition of LOX has the capacity to inhibit tumor progression and metastasis $[115,141,150]$. Indeed, administration of a LOXL2 inhibitory monoclonal antibody impaired tumor growth and metastatic colonization in a mouse model through 
effects on the tumor microenvironment [151]. Despite this, there has been relatively little attention dedicated to developing inhibitory therapeutic agents against LOX. So far, these agents include competitive inhibitors such as $\beta$ APN [115, 151] and neutralizing antibodies such as simtuzumab. Unfortunately, simtuzumab was ineffective in Phase 2 clinical trials as its administration produced no benefit in patients with pancreatic cancer [150]. However, this disappointing result may be due to the selective inhibition of LOXL2 as opposed to broad spectrum inhibition and in addition, may be due to the trial being conducted in patients with advanced cases of pancreatic cancer.

Aside from MMPs and LOX, a variety of other enzymes such as TIMPs, uPA and ADAMs may also be considered potential targets. However, experimental studies on TIMPs indicate that they mediate anti-tumor functions as well, and their inhibition may have unexpected outcomes. Regarding uPA, the potential cooperation between uPA and MMPs suggest that uPA inhibition could also hinder MMP function and thus lead to inhibition of tumor progression. A few uPA inhibitors such as upamostat have already entered clinical trials $[152,153]$ and whilst the initial results appeared promising, further trials are needed before the efficacy of uPA as a therapeutic target can be concluded.

With the collective evidence supporting the cooperative relationship between myeloid cells and the tumor ECM, it seems likely that ablation of myeloid cells or inhibition of their function may inadvertently affect the ECM. However, myeloid cells perform a wide range of physiological functions thus targeting them for the treatment of metastatic cancer may represent a significant challenge. The myeloid lineage of hematopoietic cells is an indispensable part of the innate immune system, meaning that ablation of their function is likely to result in immunosuppression. As well as providing defense against infectious pathogens, myeloid cells are known to have important anti-tumor functions, and their targeting may instead promote cancer progression by suppressing myeloid-cell mediated cancer cell destruction. As a result, a more specific approach may be to disrupt myeloid cell-ECM interactions and impair their cooperative relationship.

\section{Conclusion}

The importance of infiltrating myeloid cells and the tumor ECM for metastatic cancer progression is now widely appreciated but we are only just beginning to understand how these extrinsic factors interact with each other within the tumor microenvironment. Numerous studies have now demonstrated the ability of myeloid cells to distort the normal functions of ECM regulating enzymes, as well as mediating the pathological deposition of pro-tumor ECM components within the tumor microenvironment. In turn, certain components of the
ECM can regulate the behavior and function of myeloid cells, and this cooperative interaction appears to be a necessary factor in metastatic cancer progression.

However, it has been clear from early attempts that targeting this cooperative relationship between myeloid cells and the tumor ECM is fraught with challenges. The range of potential therapeutic targets identified is vast and many previous attempts at inhibiting key players in this relationship have failed. MMP expression by myeloid cells in the tumor microenvironment has been shown to be important for tumor progression. However, it is difficult to target MMPs specifically expressed by myeloid cells and non-specific targeting of MMPs have not led to significant inhibition of tumor progression. Additionally, inhibition of the LOX family, whilst initially promising in experimental studies, has produced disappointing results in clinic. An alternative approach to restoring normal ECM enzyme function may be to prevent the initial recruitment of myeloid cells to the tumor microenvironment. This would additionally serve to prevent myeloid cell-mediated deposition of pro-tumor ECM components and impair another important source of support for cancer progression. However, this may be difficult to achieve without disrupting myeloid cell function in patients altogether.

Despite our limited success in clinical trials, we remain positive that the restoration of normal ECM biodynamics within tumors will have significant impact on metastatic cancer progression. Given the evidence collected over the years, a larger focus needs be directed at means of impairing the cooperative relationship between myeloid cells and the tumor ECM. As well as additional efforts directed at inhibiting MMP and LOX, other ECM regulating enzymes such as uPA need to be considered and investigated further. Furthermore, an important avenue of work to pursue is to identify other potential mechanisms by which infiltrating myeloid cells influence tumor ECM. This will improve our understanding of the relationship between myeloid cells and the tumor ECM, as well as providing additional therapeutic targets for treatment of metastatic cancers.

Acknowledgments The authors acknowledge CRUK/EPSRC Oxford Cancer Imaging Centre and CRUK Oxford Centre for providing funding support.

\section{Compliance with ethical standards}

Conflicts of interest The authors declare no conflicts of interest.

Open Access This article is distributed under the terms of the Creative Commons Attribution 4.0 International License (http:// creativecommons.org/licenses/by/4.0/), which permits unrestricted use, distribution, and reproduction in any medium, provided you give appropriate credit to the original author(s) and the source, provide a link to the Creative Commons license, and indicate if changes were made. 


\section{References}

1. Hanahan D, Weinberg RA (2000) The hallmarks of cancer. Cell 100:57-70

2. Hanahan D, Weinberg RA (2011) Hallmarks of cancer: the next generation. Cell 144:646-674. doi:10.1016/j.cell.2011.02.013

3. Joyce JA, Pollard JW (2009) Microenvironmental regulation of metastasis. Nat Rev Cancer 9:239-252. doi:10.1038/nrc2618

4. Hayat MJ, Howlader N, Reichman ME, Edwards BK (2007) Cancer statistics, trends, and multiple primary cancer analyses from the Surveillance, Epidemiology, and End Results (SEER) Program. Oncologist 12:20-37. doi:10.1634/theoncologist.12-120

5. Steeg PS (2006) Tumor metastasis: mechanistic insights and clinical challenges. Nat Med 12:895-904. doi:10.1038/nm1469

6. Gupta GP, Massagué J (2006) Cancer metastasis: building a framework. Cell 127:679-695. doi:10.1016/j.cell.2006.11.001

7. Mehlen P, Puisieux A (2006) Metastasis: a question of life or death. Nat Rev Cancer 6:449-458. doi:10.1038/nrc1886

8. Paoli P, Giannoni E, Chiarugi P (2013) Anoikis molecular pathways and its role in cancer progression. Biochim Biophys Acta 1833:3481-3498. doi:10.1016/j.bbamcr.2013.06.026

9. Kolaczkowska E, Kubes P (2013) Neutrophil recruitment and function in health and inflammation. Nat Rev Immunol 13:159175. doi:10.1038/nri3399

10. Murray PJ, Wynn TA (2011) Protective and pathogenic functions of macrophage subsets. Nat Rev Immunol 11:723-737. doi:10. 1038/nri3073

11. Merad M, Sathe P, Helft J, et al. (2013) The dendritic cell lineage: ontogeny and function of dendritic cells and their subsets in the steady state and the inflamed setting. Annu Rev Immunol 31:563604. doi:10.1146/annurev-immunol-020711-074950

12. Gabrilovich DI, Ostrand-Rosenberg S, Bronte V (2012) Coordinated regulation of myeloid cells by tumours. Nat Rev Immunol 12:253-268. doi:10.1038/nri3175

13. Almand B, Clark JI, Nikitina E, et al. (1950) (2001) Increased production of immature myeloid cells in cancer patients: a mechanism of immunosuppression in cancer. J Immunol Baltim Md 166:678-689

14. Gabrilovich D (2004) Mechanisms and functional significance of tumour-induced dendritic-cell defects. Nat Rev Immunol 4:941952. doi:10.1038/nri1498

15. Condeelis J, Pollard JW (2006) Macrophages: obligate partners for tumor cell migration, invasion, and metastasis. Cell 124:263266. doi:10.1016/j.cell.2006.01.007

16. Qian B-Z, Pollard JW (2010) Macrophage diversity enhances tumor progression and metastasis. Cell 141:39-51. doi:10.1016/j. cell.2010.03.014

17. Mantovani A, Sica A (2010) Macrophages, innate immunity and cancer: balance, tolerance, and diversity. Curr Opin Immunol 22: 231-237. doi:10.1016/j.coi.2010.01.009

18. Curiel TJ, Coukos G, Zou L, et al. (2004) Specific recruitment of regulatory $\mathrm{T}$ cells in ovarian carcinoma fosters immune privilege and predicts reduced survival. Nat Med 10:942-949. doi:10.1038/ nm1093

19. Galdiero MR, Bonavita E, Barajon I, et al. (2013) Tumor associated macrophages and neutrophils in cancer. Immunobiology 218: 1402-1410. doi:10.1016/j.imbio.2013.06.003

20. Fridlender ZG, Sun J, Kim S, et al. (2009) Polarization of tumorassociated neutrophil phenotype by TGF-beta: "N1" versus "N2" TAN. Cancer Cell 16:183-194. doi:10.1016/j.ccr.2009.06.017

21. Rodriguez PC, Quiceno DG, Zabaleta J, et al. (2004) Arginase I production in the tumor microenvironment by mature myeloid cells inhibits T-cell receptor expression and antigen-specific T-cell responses. Cancer Res 64:5839-5849. doi:10.1158/0008-5472. CAN-04-0465

22. Khazaie K, Blatner NR, Khan MW, et al. (2011) The significant role of mast cells in cancer. Cancer Metastasis Rev 30:45-60. doi: 10.1007/s10555-011-9286-Z

23. de Visser KE, Eichten A, Coussens LM (2006) Paradoxical roles of the immune system during cancer development. Nat Rev Cancer 6:24-37. doi:10.1038/nrc1782

24. Yang L, Huang J, Ren X, et al. (2008) Abrogation of TGF beta signaling in mammary carcinomas recruits Gr-1 + CD11b + myeloid cells that promote metastasis. Cancer Cell 13:23-35. doi:10. 1016/j.ccr.2007.12.004

25. Wyckoff J, Wang W, Lin EY, et al. (2004) A paracrine loop between tumor cells and macrophages is required for tumor cell migration in mammary tumors. Cancer Res 64:7022-7029. doi: 10.1158/0008-5472.CAN-04-1449

26. Wyckoff JB, Wang Y, Lin EY, et al. (2007) Direct visualization of macrophage-assisted tumor cell intravasation in mammary tumors. Cancer Res 67:2649-2656. doi:10.1158/0008-5472.CAN06-1823

27. Sangaletti S, Tripodo C, Sandri S, et al. (2014) Osteopontin shapes immunosuppression in the metastatic niche. Cancer Res 74:4706 4719. doi:10.1158/0008-5472.CAN-13-3334

28. Song G, Cai Q-F, Mao Y-B, et al. (2008) Osteopontin promotes ovarian cancer progression and cell survival and increases HIF1alpha expression through the PI3-K/Akt pathway. Cancer Sci 99: 1901-1907. doi:10.1111/j.1349-7006.2008.00911.x

29. Qian B, Deng Y, Im JH, et al. (2009) A distinct macrophage population mediates metastatic breast cancer cell extravasation, establishment and growth. PLoS One 4:e6562. doi:10.1371/ journal.pone. 0006562

30. Hiratsuka S, Watanabe A, Aburatani H, Maru Y (2006) Tumourmediated upregulation of chemoattractants and recruitment of myeloid cells predetermines lung metastasis. Nat Cell Biol 8:13691375. doi:10.1038/ncb1507

31. Balkwill F (2004) Cancer and the chemokine network. Nat Rev Cancer 4:540-550. doi:10.1038/nrc1388

32. Mantovani A, Allavena P, Sozzani S, et al. (2004) Chemokines in the recruitment and shaping of the leukocyte infiltrate of tumors. Semin Cancer Biol 14:155-160. doi:10.1016/j.semcancer.2003. 10.001

33. Murdoch C, Muthana M, Coffelt SB, Lewis CE (2008) The role of myeloid cells in the promotion of tumour angiogenesis. Nat Rev Cancer 8:618-631. doi:10.1038/nrc2444

34. O'Sullivan C, Lewis CE, Harris AL, McGee JO (1993) Secretion of epidermal growth factor by macrophages associated with breast carcinoma. Lancet Lond Engl 342:148-149

35. Lewis C, Murdoch C (2005) Macrophage responses to hypoxia: implications for tumor progression and anti-cancer therapies. Am J Pathol 167:627-635. doi:10.1016/S0002-9440(10)62038-X

36. Psaila B, Lyden D (2009) The metastatic niche: adapting the foreign soil. Nat Rev Cancer 9:285-293. doi:10.1038/nrc2621

37. Kitamura T, Fujishita T, Loetscher P, et al. (2010) Inactivation of chemokine (C-C motif) receptor 1 (CCR1) suppresses colon cancer liver metastasis by blocking accumulation of immature myeloid cells in a mouse model. Proc Natl Acad Sci U S A 107: 13063-13068. doi:10.1073/pnas.1002372107

38. Zhao L, Lim SY, Gordon-Weeks AN, et al. (2013) Recruitment of a myeloid cell subset (CD11b/Gr1 mid) via CCL2/CCR2 promotes the development of colorectal cancer liver metastasis. Hepatol Baltim Md 57:829-839. doi:10.1002/hep.26094

39. Kaplan RN, Riba RD, Zacharoulis S, et al. (2005) VEGFR1positive haematopoietic bone marrow progenitors initiate the pre-metastatic niche. Nature 438:820-827. doi:10.1038/ nature 04186 
40. Lyden D, Hattori K, Dias S, et al. (2001) Impaired recruitment of bone-marrow-derived endothelial and hematopoietic precursor cells blocks tumor angiogenesis and growth. Nat Med 7:1194 1201. doi:10.1038/nm1101-1194

41. Bingle L, Brown NJ, Lewis CE (2002) The role of tumourassociated macrophages in tumour progression: implications for new anticancer therapies. J Pathol 196:254-265. doi:10.1002/ path.1027

42. Daley WP, Peters SB, Larsen M (2008) Extracellular matrix dynamics in development and regenerative medicine. J Cell Sci 121: 255-264. doi:10.1242/jcs.006064

43. Cox TR, Erler JT (2011) Remodeling and homeostasis of the extracellular matrix: implications for fibrotic diseases and cancer. Dis Model Mech 4:165-178. doi:10.1242/dmm.004077

44. Desgrosellier JS, Cheresh DA (2010) Integrins in cancer: biological implications and therapeutic opportunities. Nat Rev Cancer 10:9-22. doi:10.1038/nrc2748

45. Lu P, Weaver VM, Werb Z (2012) The extracellular matrix: a dynamic niche in cancer progression. J Cell Biol 196:395-406. doi:10.1083/jcb.201102147

46. Pickup MW, Mouw JK, Weaver VM (2014) The extracellular matrix modulates the hallmarks of cancer. EMBO Rep 15:12431253. doi: $10.15252 / \mathrm{embr} .201439246$

47. Provenzano PP, Inman DR, Eliceiri KW, et al. (2008) Collagen density promotes mammary tumor initiation and progression. BMC Med 6:11. doi:10.1186/1741-7015-6-11

48. Leight JL, Wozniak MA, Chen S, et al. (2012) Matrix rigidity regulates a switch between TGF- $\beta 1$-induced apoptosis and epithelial-mesenchymal transition. Mol Biol Cell 23:781-791. doi:10.1091/mbc.E11-06-0537

49. Brown LF, Guidi AJ, Schnitt SJ, et al. (1999) Vascular stroma formation in carcinoma in situ, invasive carcinoma, and metastatic carcinoma of the breast. Clin Cancer Res Off J Am Assoc Cancer Res 5:1041-1056

50. Bhowmick NA, Neilson EG, Moses HL (2004) Stromal fibroblasts in cancer initiation and progression. Nature 432:332-337. doi:10.1038/nature03096

51. Nishioka T, Eustace A, West C (2012) Lysyl oxidase: from basic science to future cancer treatment. Cell Struct Funct 37:75-80

52. Erler JT, Weaver VM (2009) Three-dimensional context regulation of metastasis. Clin Exp Metastasis 26:35-49. doi:10.1007/ s10585-008-9209-8

53. Lu P, Takai K, Weaver VM, Werb Z (2011) Extracellular matrix degradation and remodeling in development and disease. Cold Spring Harb Perspect Biol. doi:10.1101/cshperspect.a005058

54. Hynes RO (2009) Extracellular matrix: not just pretty fibrils. Science 326:1216-1219. doi:10.1126/science.1176009

55. Terranova VP, Liotta LA, Russo RG, Martin GR (1982) Role of laminin in the attachment and metastasis of murine tumor cells. Cancer Res 42:2265-2269

56. Wang H, Fu W, Im JH, et al. (2004) Tumor cell $\alpha 3 \beta 1$ integrin and vascular laminin-5 mediate pulmonary arrest and metastasis. J Cell Biol 164:935-941. doi:10.1083/jcb.200309112

57. Ryschich E, Khamidjanov A, Kerkadze V, et al. (2009) Promotion of tumor cell migration by extracellular matrix proteins in human pancreatic cancer. Pancreas 38:804-810. doi:10.1097/MPA. 0b013e3181b9dfda

58. Koshikawa N, Giannelli G, Cirulli V, et al. (2000) Role of cell surface metalloprotease MT1-MMP in epithelial cell migration over laminin-5. J Cell Biol 148:615-624

59. Condeelis J, Segall JE (2003) Intravital imaging of cell movement in tumours. Nat Rev Cancer 3:921-930. doi:10.1038/nrc1231

60. Provenzano PP, Eliceiri KW, Campbell JM, et al. (2006) Collagen reorganization at the tumor-stromal interface facilitates local invasion. BMC Med 4:38. doi:10.1186/1741-7015-4-38
61. Egeblad M, Rasch MG, Weaver VM (2010) Dynamic interplay between the collagen scaffold and tumor evolution. Curr Opin Cell Biol 22:697-706. doi:10.1016/j.ceb.2010.08.015

62. Engler AJ, Sen S, Sweeney HL, Discher DE (2006) Matrix elasticity directs stem cell lineage specification. Cell 126:677-689. doi:10.1016/j.cell.2006.06.044

63. Reilly GC, Engler AJ (2010) Intrinsic extracellular matrix properties regulate stem cell differentiation. J Biomech 43:55-62. doi:10. 1016/j.jbiomech.2009.09.009

64. Levental KR, Yu H, Kass L, et al. (2009) Matrix crosslinking forces tumor progression by enhancing integrin signaling. Cell 139:891-906. doi:10.1016/j.cell.2009.10.027

65. Paszek MJ, Zahir N, Johnson KR, et al. (2005) Tensional homeostasis and the malignant phenotype. Cancer Cell 8:241-254. doi: 10.1016/j.ccr.2005.08.010

66. Provenzano PP, Keely PJ (2009) The role of focal adhesion kinase in tumor initiation and progression. Cell Adhes Migr 3:347-350

67. Öhlund D, Franklin O, Lundberg E, et al. (2013) Type IV collagen stimulates pancreatic cancer cell proliferation, migration, and inhibits apoptosis through an autocrine loop. BMC Cancer 13:154. doi:10.1186/1471-2407-13-154

68. Yurchenco PD (2011) Basement membranes: cell scaffoldings and signaling platforms. Cold Spring Harb Perspect Biol. doi:10.1101/ cshperspect.a004911

69. Dixelius J, Jakobsson L, Genersch E, et al. (2004) Laminin-1 promotes angiogenesis in synergy with fibroblast growth factor by distinct regulation of the gene and protein expression profile in endothelial cells. J Biol Chem 279:23766-23772. doi:10.1074/ jbc.M311675200

70. Davis GE, Senger DR (2005) Endothelial extracellular matrix: biosynthesis, remodeling, and functions during vascular morphogenesis and neovessel stabilization. Circ Res 97:1093-1107. doi: 10.1161/01.RES.0000191547.64391.e3

71. DeHahn KC, Gonzales M, Gonzalez AM, et al. (2004) The $\alpha 4$ laminin subunit regulates endothelial cell survival. Exp Cell Res 294:281-289. doi:10.1016/j.yexcr.2003.11.006

72. Gonzalez AM, Gonzales M, Herron GS, et al. (2002) Complex interactions between the laminin alpha 4 subunit and integrins regulate endothelial cell behavior in vitro and angiogenesis in vivo. Proc Natl Acad Sci U S A 99:16075-16080. doi:10. 1073/pnas.252649399

73. Wyckoff JB, Jones JG, Condeelis JS, Segall JE (2000) A critical step in metastasis: in vivo analysis of intravasation at the primary tumor. Cancer Res 60:2504-2511

74. Weidner N, Semple JP, Welch WR, Folkman J (1991) Tumor angiogenesis and metastasis-correlation in invasive breast carcinoma. N Engl J Med 324:1-8. doi:10.1056/ NEJM199101033240101

75. Weidner N, Carroll PR, Flax J, et al. (1993) Tumor angiogenesis correlates with metastasis in invasive prostate carcinoma. Am J Pathol 143:401-409

76. Page-McCaw A, Ewald AJ, Werb Z (2007) Matrix metalloproteinases and the regulation of tissue remodelling. Nat Rev Mol Cell Biol 8:221-233. doi:10.1038/nrm2125

77. Endo K, Takino T, Miyamori H, et al. (2003) Cleavage of syndecan-1 by membrane type matrix metalloproteinase- 1 stimulates cell migration. J Biol Chem 278:40764-40770. doi:10.1074/ jbc.M306736200

78. Kessenbrock K, Plaks V, Werb Z (2010) Matrix metalloproteinases: regulators of the tumor microenvironment. Cell 141:52-67. doi:10.1016/j.cell.2010.03.015

79. Gialeli C, Theocharis AD, Karamanos NK (2011) Roles of matrix metalloproteinases in cancer progression and their pharmacological targeting. FEBS J 278:16-27. doi:10.1111/j.1742-4658.2010. 07919.x 
80. Jodele S, Blavier L, Yoon JM, DeClerck YA (2006) Modifying the soil to affect the seed: role of stromal-derived matrix metalloproteinases in cancer progression. Cancer Metastasis Rev 25:35-43. doi:10.1007/s10555-006-7887-8

81. Heslin MJ, Yan J, Johnson MR, et al. (2001) Role of matrix metalloproteinases in colorectal carcinogenesis. Ann Surg 233:786792

82. Liu Z, Ivanoff A, Klominek J (2001) Expression and activity of matrix metalloproteases in human malignant mesothelioma cell lines. Int J Cancer J Int Cancer 91:638-643

83. Yang W, Arii S, Gorrin-Rivas MJ, et al. (2001) Human macrophage metalloelastase gene expression in colorectal carcinoma and its clinicopathologic significance. Cancer 91:1277-1283

84. Sternlicht MD, Bergers G (2000) Matrix metalloproteinases as emerging targets in anticancer therapy: status and prospects. Emerg Ther Targets 4:609-633. doi:10.1517/14728222.4.5.609

85. Airola K, Fusenig NE (2001) Differential stromal regulation of MMP-1 expression in benign and malignant keratinocytes. $\mathrm{J}$ Investig Dermatol 116:85-92. doi:10.1046/j.1523-1747.2001. 00223.x

86. McKerrow JH, Bhargava V, Hansell E, et al. (2000) A functional proteomics screen of proteases in colorectal carcinoma. Mol Med Camb Mass 6:450-460

87. Kim J, Yu W, Kovalski K, Ossowski L (1998) Requirement for specific proteases in cancer cell intravasation as revealed by a novel semiquantitative PCR-based assay. Cell 94:353-362

88. Itoh T, Tanioka M, Matsuda H, et al. (1999) Experimental metastasis is suppressed in MMP-9-deficient mice. Clin Exp Metastasis 17:177-181

89. Coussens LM, Tinkle CL, Hanahan D, Werb Z (2000) MMP-9 supplied by bone marrow-derived cells contributes to skin carcinogenesis. Cell 103:481-490

90. Têtu B, Brisson J, Wang CS, et al. (2006) The influence of MMP14, TIMP-2 and MMP-2 expression on breast cancer prognosis. Breast Cancer Res BCR 8:R28. doi:10.1186/bcr1503

91. Zhang B, Cao X, Liu Y, et al. (2008) Tumor-derived matrix metalloproteinase-13 (MMP-13) correlates with poor prognoses of invasive breast cancer. BMC Cancer 8:83. doi:10.1186/14712407-8-83

92. LJ v 't V, Dai H, de Vijver MJ v, et al. (2002) Gene expression profiling predicts clinical outcome of breast cancer. Nature 415: 530-536. doi:10.1038/415530a

93. Minn AJ, Gupta GP, Siegel PM, et al. (2005) Genes that mediate breast cancer metastasis to lung. Nature 436:518-524. doi:10. 1038/nature03799

94. Fang J, Shing Y, Wiederschain D, et al. (2000) Matrix metalloproteinase- 2 is required for the switch to the angiogenic phenotype in a tumor model. Proc Natl Acad Sci 97:3884-3889. doi:10.1073/pnas.97.8.3884

95. Bergers G, Brekken R, McMahon G, et al. (2000) Matrix metalloproteinase-9 triggers the angiogenic switch during carcinogenesis. Nat Cell Biol 2:737-744. doi:10.1038/35036374

96. Krüger A, Arlt MJE, Gerg M, et al. (2005) Antimetastatic activity of a novel mechanism-based gelatinase inhibitor. Cancer Res 65: 3523-3526. doi:10.1158/0008-5472.CAN-04-3570

97. Sternlicht MD, Lochter A, Sympson CJ, et al. (1999) The stromal proteinase MMP3/stromelysin-1 promotes mammary carcinogenesis. Cell 98:137-146

98. Lochter A, Galosy S, Muschler J, et al. (1997) Matrix metalloproteinase stromelysin-1 triggers a cascade of molecular alterations that leads to stable epithelial-to-mesenchymal conversion and a premalignant phenotype in mammary epithelial cells. J Cell Biol 139:1861-1872

99. Mott JD, Werb Z (2004) Regulation of matrix biology by matrix metalloproteinases. Curr Opin Cell Biol 16:558-564. doi:10. 1016/j.ceb.2004.07.010
100. Pirilä E, Sharabi A, Salo T, et al. (2003) Matrix metalloproteinases process the laminin-5 gamma 2-chain and regulate epithelial cell migration. Biochem Biophys Res Commun 303:1012-1017

101. Petitclerc E, Strömblad S, von STL, et al. (1999) Integrin $\alpha \mathrm{V} \beta 3$ Promotes M21 Melanoma Growth in Human Skin by Regulating Tumor Cell Survival. Cancer Res 59:2724-2730

102. Xu J, Rodriguez D, Petitclerc E, et al. (2001) Proteolytic exposure of a cryptic site within collagen type IV is required for angiogenesis and tumor growth in vivo. J Cell Biol 154:1069-1079. doi:10. 1083/jcb.200103111

103. Balbín M, Fueyo A, Tester AM, et al. (2003) Loss of collagenase2 confers increased skin tumor susceptibility to male mice. Nat Genet 35:252-257. doi:10.1038/ng1249

104. Witty JP, Lempka T, Coffey RJ, Matrisian LM (1995) Decreased tumor formation in 7,12-dimethylbenzanthracene-treated stromelysin-1 transgenic mice is associated with alterations in mammary epithelial cell apoptosis. Cancer Res 55:1401-1406

105. Takeha S, Fujiyama Y, Bamba T, et al. (1997) Stromal expression of MMP-9 and urokinase receptor is inversely associated with liver metastasis and with infiltrating growth in human colorectal cancer: a novel approach from immune/inflammatory aspect. Jpn J Cancer Res Gann 88:72-81

106. Fingleton B (2003) Matrix metalloproteinase inhibitors for cancer therapy:the current situation and future prospects. Expert Opin Ther Targets 7:385-397. doi:10.1517/14728222.7.3.385

107. Bergers G, Javaherian K, Lo KM, et al. (1999) Effects of angiogenesis inhibitors on multistage carcinogenesis in mice. Science 284:808-812

108. Pozzi A, Moberg PE, Miles LA, et al. (2000) Elevated matrix metalloprotease and angiostatin levels in integrin alpha 1 knockout mice cause reduced tumor vascularization. Proc Natl Acad Sci U S A 97:2202-2207. doi:10.1073/pnas.040378497

109. Brew K, Dinakarpandian D, Nagase H (2000) Tissue inhibitors of metalloproteinases: evolution, structure and function. Biochim Biophys Acta 1477:267-283

110. Buck TB, Yoshiji H, Harris SR, et al. (1999) The effects of sustained elevated levels of circulating tissue inhibitor of metalloproteinases- 1 on the development of breast cancer in mice. Ann N Y Acad Sci 878:732-735

111. Ikenaka Y, Yoshiji H, Kuriyama S, et al. (2003) Tissue inhibitor of metalloproteinases-1 (TIMP-1) inhibits tumor growth and angiogenesis in the TIMP-1 transgenic mouse model. Int J Cancer J Int Cancer 105:340-346. doi:10.1002/ijc.11094

112. Gong Y, Scott E, Lu R, et al. (2013) TIMP-1 promotes accumulation of cancer associated fibroblasts and cancer progression. PLoS One 8:e77366. doi:10.1371/journal.pone.0077366

113. Remacle A, McCarthy K, Noël A, et al. (2000) High levels of TIMP-2 correlate with adverse prognosis in breast cancer. Int $\mathrm{J}$ Cancer J Int Cancer 89:118-121

114. Payne SL, Hendrix MJC, Kirschmann DA (2007) Paradoxical roles for lysyl oxidases in cancer-a prospect. J Cell Biochem 101:1338-1354. doi:10.1002/jcb.21371

115. Erler JT, Bennewith KL, Nicolau M, et al. (2006) Lysyl oxidase is essential for hypoxia-induced metastasis. Nature 440:1222-1226. doi:10.1038/nature04695

116. Kirschmann DA, Seftor EA, Fong SFT, et al. (2002) A molecular role for lysyl oxidase in breast cancer invasion. Cancer Res 62 : 4478-4483

117. Peinado H, la Cruz M DC I-d, Olmeda D, al. e (2005) A molecular role for lysyl oxidase-like 2 enzyme in snail regulation and tumor progression. EMBO J 24:3446-3458. doi:10.1038/sj.emboj. 7600781

118. Barker HE, Chang J, Cox TR, et al. (2011) LOXL2-mediated matrix remodeling in metastasis and mammary gland involution. Cancer Res 71:1561-1572. doi:10.1158/0008-5472.CAN-102868 
119. Smith HW, Marshall CJ (2010) Regulation of cell signalling by uPAR. Nat Rev Mol Cell Biol 11:23-36. doi:10.1038/nrm2821

120. Weigelt B, Peterse JL, LJ v 't V (2005) Breast cancer metastasis: markers and models. Nat Rev Cancer 5:591-602. doi:10.1038/ $\operatorname{nrc} 1670$

121. Shiomi H, Eguchi Y, Tani T, et al. (2000) Cellular distribution and clinical value of urokinase-type plasminogen activator, its receptor, and plasminogen activator inhibitor-2 in esophageal squamous cell carcinoma. Am J Pathol 156:567-575. doi:10.1016/S00029440(10)64761-X

122. Edwards DR, Handsley MM, Pennington CJ (2008) The ADAM metalloproteinases. Mol Asp Med 29:258-289. doi:10.1016/j. mam.2008.08.001

123. Murphy G (2008) The ADAMs: signalling scissors in the tumour microenvironment. Nat Rev Cancer 8:929-941. doi:10.1038/ $\operatorname{nrc} 2459$

124. Maretzky T, Reiss K, Ludwig A, et al. (2005) ADAM10 mediates E-cadherin shedding and regulates epithelial cell-cell adhesion, migration, and beta-catenin translocation. Proc Natl Acad Sci U S A 102:9182-9187. doi:10.1073/pnas.0500918102

125. Mazzocca A, Coppari R, De Franco R, et al. (2005) A secreted form of ADAM9 promotes carcinoma invasion through tumorstromal interactions. Cancer Res 65:4728-4738. doi:10.1158/ 0008-5472.CAN-04-4449

126. Kveiborg M, Fröhlich C, Albrechtsen R, et al. (2005) A role for ADAM12 in breast tumor progression and stromal cell apoptosis. Cancer Res 65:4754-4761. doi:10.1158/0008-5472.CAN-050262

127. Grützmann R, Lüttges J, Sipos B, et al. (2004) ADAM9 expression in pancreatic cancer is associated with tumour type and is a prognostic factor in ductal adenocarcinoma. Br J Cancer 90:10531058. doi:10.1038/sj.bjc. 6601645

128. Shintani Y, Higashiyama S, Ohta M, et al. (2004) Overexpression of ADAM9 in non-small cell lung cancer correlates with brain metastasis. Cancer Res 64:4190-4196. doi:10.1158/0008-5472. CAN-03-3235

129. Valkovskaya N, Kayed H, Felix K, et al. (2007) ADAM8 expression is associated with increased invasiveness and reduced patient survival in pancreatic cancer. J Cell Mol Med 11:1162-1174. doi: 10.1111/j.1582-4934.2007.00082.x

130. Davies B, Miles DW, Happerfield LC, et al. (1993) Activity of type IV collagenases in benign and malignant breast disease. Br J Cancer 67:1126-1131

131. Davies B, Waxman J, Wasan H, et al. (1993) Levels of matrix metalloproteases in bladder cancer correlate with tumor grade and invasion. Cancer Res 53:5365-5369

132. Naylor MS, Stamp GW, Davies BD, Balkwill FR (1994) Expression and activity of MMPS and their regulators in ovarian cancer. Int J Cancer J Int Cancer 58:50-56

133. Hiratsuka S, Nakamura K, Iwai S, et al. (2002) MMP9 induction by vascular endothelial growth factor receptor-1 is involved in lung-specific metastasis. Cancer Cell 2:289-300

134. Ardi VC, Van den Steen PE, Opdenakker G, et al. (2009) Neutrophil MMP-9 proenzyme, unencumbered by TIMP-1, undergoes efficient activation in vivo and catalytically induces angiogenesis via a basic fibroblast growth factor (FGF-2)/FGFR-2 pathway. J Biol Chem 284:25854-25866. doi:10.1074/jbc.M109. 033472

135. Xu Y, Hagege J, Doublet JD, et al. (1997) Endothelial and macrophage upregulation of urokinase receptor expression in human renal cell carcinoma. Hum Pathol 28:206-213

136. Hildenbrand R, Wolf G, Böhme B, et al. (1999) Urokinase plasminogen activator receptor (CD87) expression of tumorassociated macrophages in ductal carcinoma in situ, breast cancer, and resident macrophages of normal breast tissue. J Leukoc Biol 66:40-49
137. Hildenbrand R, Dilger I, Hörlin A, Stutte HJ (1995) Urokinase and macrophages in tumour angiogenesis. Br J Cancer 72:818-823

138. D'Haese A, Wuyts A, Dillen C, et al. (2000) In vivo neutrophil recruitment by granulocyte chemotactic protein-2 is assisted by gelatinase B/MMP-9 in the mouse. J Interferon Cytokine Res Off J Int Soc Interferon Cytokine Res 20:667-674. doi:10.1089/ 107999000414853

139. Li Q, Park PW, Wilson CL, Parks WC (2002) Matrilysin shedding of syndecan-1 regulates chemokine mobilization and transepithelial efflux of neutrophils in acute lung injury. Cell 111:635-646

140. Haro H, Crawford HC, Fingleton B, et al. (2000) Matrix metalloproteinase-3-dependent generation of a macrophage chemoattractant in a model of herniated disc resorption. J Clin Invest 105:133-141. doi:10.1172/JCI7090

141. Erler JT, Bennewith KL, Cox TR, et al. (2009) Hypoxia-induced lysyl oxidase is a critical mediator of bone marrow cell recruitment to form the premetastatic niche. Cancer Cell 15:35-44. doi:10. 1016/j.ccr.2008.11.012

142. Lim SY, Gordon-Weeks A, Allen D, et al. (2015) Cd11b(+) myeloid cells support hepatic metastasis through down-regulation of angiopoietin-like 7 in cancer cells. Hepatol Baltim Md 62:521533. doi:10.1002/hep. 27838

143. Paschos KA, Majeed AW, Bird NC (2010) Role of Kupffer cells in the outgrowth of colorectal cancer liver metastases. Hepatol Res Off J Jpn Soc Hepatol 40:83-94. doi:10.1111/j.1872-034X.2009. 00578.x

144. Wen SW, Ager EI, Christophi C (2013) Bimodal role of Kupffer cells during colorectal cancer liver metastasis. Cancer Biol Ther 14:606-613. doi:10.4161/cbt.24593

145. Friedman SL, Arthur MJ (1989) Activation of cultured rat hepatic lipocytes by Kupffer cell conditioned medium. Direct enhancement of matrix synthesis and stimulation of cell proliferation via induction of platelet-derived growth factor receptors. J Clin InvestJ Clin Invest 84:1780-1785. doi:10.1172/JCI114362

146. Sosa MS, Bragado P, Aguirre-Ghiso JA (2014) Mechanisms of disseminated cancer cell dormancy: an awakening field. Nat Rev Cancer 14:611-622. doi:10.1038/nrc3793

147. Overall CM, Kleifeld O (2006) Validating matrix metalloproteinases as drug targets and anti-targets for cancer therapy. Nat Rev Cancer 6:227-239. doi:10.1038/nrc1821

148. Coussens LM, Fingleton B, Matrisian LM (2002) Matrix metalloproteinase inhibitors and cancer: trials and tribulations. Science 295:2387-2392. doi:10.1126/science. 1067100

149. King J, Zhao J, Clingan P, Morris D (2003) Randomised double blind placebo control study of adjuvant treatment with the metalloproteinase inhibitor, Marimastat in patients with inoperable colorectal hepatic metastases: significant survival advantage in patients with musculoskeletal side-effects. Anticancer Res 23:639645

150. Barker HE, Cox TR, Erler JT (2012) The rationale for targeting the LOX family in cancer. Nat Rev Cancer 12:540-552. doi:10.1038/ nrc3319

151. Barry-Hamilton V, Spangler R, Marshall D, et al. (2010) Allosteric inhibition of lysyl oxidase-like-2 impedes the development of a pathologic microenvironment. Nat Med 16:1009-1017. doi:10. 1038/nm.2208

152. Heinemann V, Ebert MP, Laubender RP, et al. (2013) Phase II randomised proof-of-concept study of the urokinase inhibitor upamostat (WX-671) in combination with gemcitabine compared with gemcitabine alone in patients with non-resectable, locally advanced pancreatic cancer. Br J Cancer 108:766-770. doi:10. 1038/bjc. 2013.62

153. Goldstein LJ (2008) Experience in Phase I Trials and an Upcoming Phase II Study with uPA Inhibitors in Metastatic Breast Cancer. Breast Care 3:25-28. doi:10.1159/000151733 
154. Boire A, Covic L, Agarwal A, et al. (2005) PAR1 is a matrix metalloprotease-1 receptor that promotes invasion and tumorigenesis of breast cancer cells. Cell 120:303-313. doi:10.1016/j.cell. 2004.12.018

155. Foley CJ, Luo C, O'Callaghan K, et al. (2012) Matrix metalloprotease-1a promotes tumorigenesis and metastasis. $\mathrm{J}$ Biol Chem 287:24330-24338. doi:10.1074/jbc.M112.356303

156. Liu H, Kato Y, Erzinger SA, et al. (2012) The role of MMP-1 in breast cancer growth and metastasis to the brain in a xenograft model. BMC Cancer 12:583. doi:10.1186/1471-2407-12-583

157. Shiozawa J, Ito M, Nakayama T, et al. (2000) Expression of matrix metalloproteinase-1 in human colorectal carcinoma. Mod Pathol Off J U S Can Acad Pathol Inc 13:925-933. doi:10.1038/ modpathol.3880169

158. Leinonen T, Pirinen R, Böhm J, et al. (2008) Increased expression of matrix metalloproteinase-2 (MMP-2) predicts tumour recurrence and unfavourable outcome in non-small cell lung cancer. Histol Histopathol 23:693-700

159. Mendes O, Kim H-T, Stoica G (2005) Expression of MMP2, MMP9 and MMP3 in breast cancer brain metastasis in a rat model. Clin Exp Metastasis 22:237-246. doi:10.1007/s10585-005-81156

160. Kim TS, Kim YB (1999) Correlation between expression of matrix metalloproteinase-2 (MMP-2), and matrix metalloproteinase-9 (MMP-9) and angiogenesis in colorectal adenocarcinoma. J Korean Med Sci 14:263-270

161. Mehner C, Miller E, Khauv D, et al. (2014) Tumor cell-derived MMP3 orchestrates Rac1b and tissue alterations that promote pancreatic adenocarcinoma. Mol Cancer Res MCR 12:1430-1439. doi:10.1158/1541-7786.MCR-13-0557-T

162. Mitsiades N, Yu WH, Poulaki V, et al. (2001) Matrix metalloproteinase-7-mediated cleavage of Fas ligand protects tumor cells from chemotherapeutic drug cytotoxicity. Cancer Res 61:577-581

163. Liu H, Zhang T, Li X, et al. (2008) Predictive value of MMP-7 expression for response to chemotherapy and survival in patients with non-small cell lung cancer. Cancer Sci 99:2185-2192. doi: 10.1111/j.1349-7006.2008.00922.x

164. Nakamura M, Miyamoto S, Maeda H, et al. (2005) Matrix metalloproteinase-7 degrades all insulin-like growth factor binding proteins and facilitates insulin-like growth factor bioavailability. Biochem Biophys Res Commun 333:1011-1016. doi:10. 1016/j.bbrc.2005.06.010

165. Strand S, Vollmer P, van den Abeelen L, et al. (2004) Cleavage of CD95 by matrix metalloproteinase- 7 induces apoptosis resistance in tumour cells. Oncogene 23:3732-3736. doi:10.1038/sj.onc. 1207387

166. Decock J, Hendrickx W, Vanleeuw U, et al. (2008) Plasma MMP1 and MMP8 expression in breast cancer: Protective role of MMP8 against lymph node metastasis. BMC Cancer 8:77. doi:10.1186/ 1471-2407-8-77

167. Korpi JT, Kervinen V, Mäklin H, et al. (2008) Collagenase-2 (matrix metalloproteinase-8) plays a protective role in tongue cancer. Br J Cancer 98:766-775. doi:10.1038/sj.bjc.6604239

168. Ahn G-O, Brown JM (2008) Matrix metalloproteinase-9 is required for tumor vasculogenesis but not for angiogenesis: role of bone marrow-derived myelomonocytic cells. Cancer Cell 13:193205. doi:10.1016/j.ccr.2007.11.032

169. Merdad A, Karim S, Schulten H-J, et al. (2014) Expression of matrix metalloproteinases (MMPs) in primary human breast cancer: MMP-9 as a potential biomarker for cancer invasion and metastasis. Anticancer Res 34:1355-1366

170. Andarawewa KL, Boulay A, Masson R, et al. (2003) Dual stromelysin-3 function during natural mouse mammary tumor virus-ras tumor progression. Cancer Res 63:5844-5849
171. Jia L, Wang S, Cao J, et al. (2007) siRNA targeted against matrix metalloproteinase 11 inhibits the metastatic capability of murine hepatocarcinoma cell Hca-F to lymph nodes. Int J Biochem Cell Biol 39:2049-2062. doi:10.1016/j.biocel.2007.05.023

172. Deng H, Guo R-F, Li W-M, et al. (2005) Matrix metalloproteinase 11 depletion inhibits cell proliferation in gastric cancer cells. Biochem Biophys Res Commun 326:274-281. doi:10.1016/j. bbrc.2004.11.027

173. Qu P, Du H, Wang X, Yan C (2009) Matrix metalloproteinase 12 overexpression in lung epithelial cells plays a key role in emphysema to lung bronchioalveolar adenocarcinoma transition. Cancer Res 69:7252-7261. doi:10.1158/0008-5472.CAN-09-0577

174. Sabeh F, Ota I, Holmbeck K, et al. (2004) Tumor cell traffic through the extracellular matrix is controlled by the membraneanchored collagenase MT1-MMP. J Cell Biol 167:769-781. doi: 10.1083/jcb.200408028

175. Sounni NE, Dehne K, van Kempen L, et al. (2010) Stromal regulation of vessel stability by MMP14 and TGF $\beta$. Dis Model Mech 3:317-332. doi:10.1242/dmm.003863

176. Pesta M, Kulda V, Kucera R, et al. (2011) Prognostic significance of TIMP-1 in non-small cell lung cancer. Anticancer Res 31:40314038

177. Seubert B, Grünwald B, Kobuch J, et al. (2015) Tissue inhibitor of metalloproteinases (TIMP)-1 creates a premetastatic niche in the liver through SDF-1/CXCR4-dependent neutrophil recruitment in mice. Hepatol Baltim Md 61:238-248. doi:10.1002/hep.27378

178. Valente P, Fassina G, Melchiori A, et al. (1998) TIMP-2 overexpression reduces invasion and angiogenesis and protects B16F10 melanoma cells from apoptosis. Int J Cancer J Int Cancer 75:246-253

179. Zhu M, Zhang N, He S, et al. (2014) MicroRNA-106a targets TIMP2 to regulate invasion and metastasis of gastric cancer. FEBS Lett 588:600-607. doi:10.1016/j.febslet.2013.12.028

180. Baker A-M, Bird D, Lang G, et al. (2013) Lysyl oxidase enzymatic function increases stiffness to drive colorectal cancer progression through FAK. Oncogene 32:1863-1868. doi:10.1038/onc.2012. 202

181. Peinado H, Moreno-Bueno G, Hardisson D, et al. (2008) Lysyl oxidase-like 2 as a new poor prognosis marker of squamous cell carcinomas. Cancer Res 68:4541-4550. doi:10.1158/0008-5472. CAN-07-6345

182. Peng L, Ran Y-L, Hu H, et al. (2009) Secreted LOXL2 is a novel therapeutic target that promotes gastric cancer metastasis via the Src/FAK pathway. Carcinogenesis 30:1660-1669. doi:10.1093/ carcin/bgp178

183. Akiri G, Sabo E, Dafni H, et al. (2003) Lysyl oxidase-related protein-1 promotes tumor fibrosis and tumor progression in vivo. Cancer Res 63:1657-1666

184. Holtmeier C, Görögh T, Beier U, et al. (2003) Overexpression of a novel lysyl oxidase-like gene in human head and neck squamous cell carcinomas. Anticancer Res 23:2585-2591

185. Weise JB, Rudolph P, Heiser A, et al. (1990) (2008) LOXL4 is a selectively expressed candidate diagnostic antigen in head and neck cancer. Eur J Cancer Oxf Engl 44:1323-1331. doi:10.1016/ j.ejca.2008.03.026

186. Sebban S, Davidson B, Reich R (2009) Lysyl oxidase-like 4 is alternatively spliced in an anatomic site-specific manner in tumors involving the serosal cavities. Virchows Arch Int J Pathol 454:7179. doi:10.1007/s00428-008-0694-6

187. Görögh T, Weise JB, Holtmeier C, et al. (2007) Selective upregulation and amplification of the lysyl oxidase like-4 (LOXL4) gene in head and neck squamous cell carcinoma. J Pathol 212:74-82. doi:10.1002/path.2137

188. Zhang L, Zhao Z-S, Ru G-Q, Ma J (2006) Correlative studies on uPA mRNA and UPAR mRNA expression with vascular endothelial growth factor, microvessel density, progression and survival 
time of patients with gastric cancer. World J Gastroenterol 12: 3970-3976

189. Bauer TW, Liu W, Fan F, et al. (2005) Targeting of urokinase plasminogen activator receptor in human pancreatic carcinoma cells inhibits c-Met- and insulin-like growth factor-I receptor-mediated migration and invasion and orthotopic tumor growth in mice. Cancer Res 65:7775-7781. doi:10.1158/0008-5472.CAN05-0946

190. Ishikawa N, Daigo Y, Yasui W, et al. (2004) ADAM8 as a novel serological and histochemical marker for lung cancer. Clin Cancer Res Off J Am Assoc Cancer Res 10:8363-8370. doi:10.1158/ 1078-0432.CCR-04-1436

191. Fritzsche FR, Jung M, Tölle A, et al. (2008) ADAM9 expression is a significant and independent prognostic marker of PSA relapse in prostate cancer. Eur Urol 54:1097-1106. doi:10.1016/j.eururo. 2007.11.034

192. Peduto L, Reuter VE, Shaffer DR, et al. (2005) Critical function for ADAM9 in mouse prostate cancer. Cancer Res 65:9312-9319. doi:10.1158/0008-5472.CAN-05-1063

193. Ko S-Y, Lin S-C, Wong Y-K, et al. (2007) Increase of disintergin metalloprotease 10 (ADAM10) expression in oral squamous cell carcinoma. Cancer Lett 245:33-43. doi:10.1016/j.canlet.2005.10. 019

194. Kirkin V, Cahuzac N, Guardiola-Serrano F, et al. (2007) The Fas ligand intracellular domain is released by ADAM10 and SPPL2a cleavage in T-cells. Cell Death Differ 14:1678-1687. doi:10.1038/ sj.cdd. 4402175
195. Peduto L, Reuter VE, Sehara-Fujisawa A, et al. (2006) ADAM12 is highly expressed in carcinoma-associated stroma and is required for mouse prostate tumor progression. Oncogene 25:5462-5466. doi:10.1038/sj.onc. 1209536

196. Roy R, Wewer UM, Zurakowski D, et al. (2004) ADAM 12 cleaves extracellular matrix proteins and correlates with cancer status and stage. J Biol Chem 279:51323-51330. doi:10.1074/ jbc.M409565200

197. Schütz A, Härtig W, Wobus M, et al. (2005) Expression of ADAM15 in lung carcinomas. Virchows Arch Int J Pathol 446: 421-429. doi:10.1007/s00428-004-1193-Z

198. Kuefer R, Day KC, Kleer CG, et al. (2006) ADAM15 disintegrin is associated with aggressive prostate and breast cancer disease. Neoplasia N Y N 8:319-329. doi:10.1593/neo.05682

199. McGowan PM, Ryan BM, Hill ADK, et al. (2007) ADAM-17 expression in breast cancer correlates with variables of tumor progression. Clin Cancer Res Off J Am Assoc Cancer Res 13:23352343. doi:10.1158/1078-0432.CCR-06-2092

200. McGowan PM, McKiernan E, Bolster F, et al. (2008) ADAM-17 predicts adverse outcome in patients with breast cancer. Ann Oncol Off J Eur Soc Med Oncol ESMO 19:1075-1081. doi:10. 1093/annonc/mdm609

201. Zheng X, Jiang F, Katakowski M, et al. (2007) Inhibition of ADAM17 reduces hypoxia-induced brain tumor cell invasiveness. Cancer Sci 98:674-684. doi:10.1111/j.13497006.2007.00440.x 